\title{
Advancements in non-destructive control of efficiency of electrochemical repair techniques
}

\author{
I. Martínez*, C. Andrade, M. Castellote and P. García de Viedma
}

The main electrochemical techniques used for reducing corrosion on reinforced structures are cathodic protection (CP), electrochemical chloride extraction (ECE) and realkalisation (ER). Traditionally, for controlling the efficiency of $\mathrm{CP}$, standard methods based in the depolarisation of rebar are used, with inconvenience of requiring the interruption of the protection current even for several hours. Concerning ECE and ER, the usual methods involve extraction and chemical analysis (chloride and hydroxyl ions respectively) of cores from the structure. In this paper, some non-destructive methods for monitoring the performance of the electrochemical repair techniques, are presented and analysed. In CP, a new developed methodology, called passivity verification technique (PVT), which uses the electrochemical impedance spectroscopy concept, is described. This is a fast method that does not require interruption of the cathodic protection current and the results obtained are in agreement with those obtained by standard depolarisation methods. As long as ECE and ER are concerned, the corrosion potential and corrosion rate measured by the polarisation resistance technique are the suggested non-destructive indicators of the efficiency of the technique at the end of the treatment. Additionally, for ER, the detection of a sudden increase in the intensity of electrical current passing, and a parallel establishment of electro-osmotic flux, is also postulated as a key parameter for practical control during the application of the efficiency of the realkalisation. Finally, it is also presented a new parameter 'standardised by the resistance charges (SRC)', which would be a more indicative parameter than simple recording the coulombs to check the efficiency during ECE treatment.

Keywords: Concrete, Cathodic protection, Electrochemical chloride extraction, Realkalisation, Electro-osmotic flux

\section{Introduction}

The electrochemical techniques used for repair/protection of concrete structures damaged because of reinforcement corrosion are: cathodic protection (CP), electrochemical chloride extraction (ECE) and electrochemical realkalisation (ER). Among these three techniques, cathodic protection is the most ancient. ${ }^{1}$ It has been used widely in steel structures immersed in water (such as boats or off shore platforms) as well as buried structures (pipe lines). Its principles are known since the nineteenth century, but the application to concrete structures did not start until around 1955 (in submerged or buried structures). ${ }^{2}$ In 1970, CP started to be used in concrete aerial structures, and in the 1990s, it was applied as a preventive technique (cathodic prevention). ${ }^{3}$ Cathodic protection is regulated and standardised in different countries. ${ }^{4-7}$

The ECE and ER are relatively recent methods, ${ }^{8}$ and they are still being developed nowadays. This document

Instituto Eduardo Torroja (CSIC), C/Serrano Galvache no. 4, 28033 Madrid, España

*Corresponding author, email isabelms@ietcc.csic.es describes the most important aspects implied on them, including present methods of monitoring their efficiency.

These techniques are based on making the metal to act as cathode and therefore, on inducing several electrochemical phenomena on its surface: the build-up of $\mathrm{OH}^{-}$due to the cathodic reduction of the oxygen) $\mathrm{O}_{2}+\mathrm{H}_{2} \mathrm{O}+\mathrm{e}^{-} \rightarrow 4 \mathrm{OH}^{-}$and the removal of negative ions (chlorides are those of particular interest) (Fig. 1). In the case of ER, an additional effect is the penetration of the external electrolyte by means of electroosmosis. ${ }^{9,10,11}$ Although in the case of the $\mathrm{CP}$, due to the relatively low currents applied, these phenomena may not be significant; however, they are significant and one of the reasons attributed to the reduction of the corrosion rate.

Then, in the case of $\mathrm{CP}$, the reinforcement is induced to be cathode connecting it to a sacrificial anode that polarises the bar towards the cathodic direction or applying a current of appropriate polarity. Being cathode, the steel bars reduce the number of anodic zones in its surface and therefore, the corrosion process can be reduced. However, the protection of the bars (suppression of anodic zones) will depend on the current applied or the potential reached. ${ }^{12}$ If the potential is not enough shifted towards the cathodic side, then the 


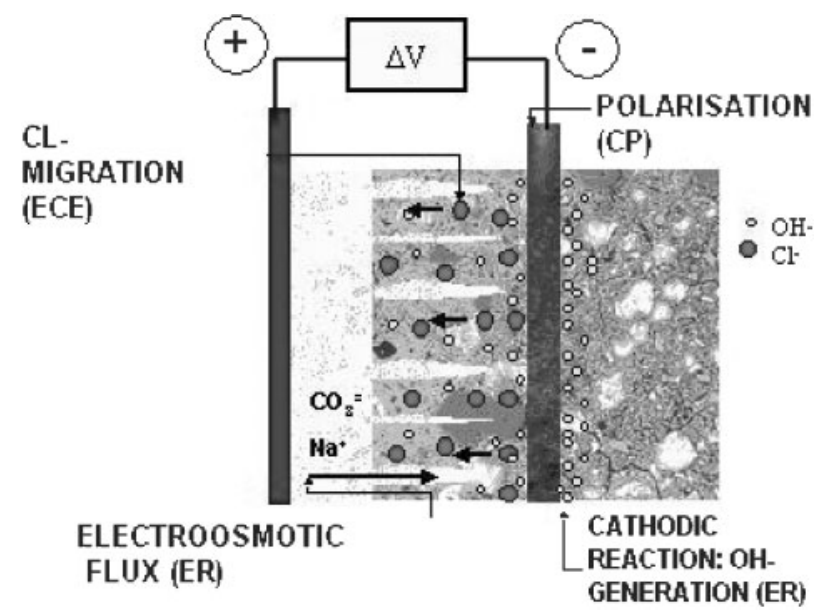

1 Schematic representation of different processes that occurs when electrochemical repair techniques are applied to reinforcement

protection level may be insufficient, and the corrosion can progress although the bar is acting as a cathode. Therefore, it is a normal practice to control the efficiency of the $\mathrm{CP}$, understanding by efficiency, how much effective the current is applied for suppressing the anodic behaviour in the reinforcement. The methods normally used for verifying this efficiency are: instant off potential and depolarisation decay. ${ }^{4,7}$

These controlling methods are based on the attempt to verify whether the metal has reduced its corrosion rate to negligible values by measuring: the potential in cathodically polarised situation but without the ohmic drop (instant off potential) and the potential after a certain time of depolarisation. In both methods, the aim is to verify whether instant off potential is cathodic enough to assure that any anodic activity remains ${ }^{12}$ or the depolarised potential reaches values to demonstrate that the steel is being adequately polarised by CP. The need to verify the cathodic potential appears due to the fact that it is not needed only for the metal to be the cathode, but also that the anodic contribution disappears. This is only achieved by lowering the potential below a certain value where the corrosion stops. ${ }^{13}$

In the case of ECE, the current applied is much higher than for CP, but instead of being permanently applied, the period of application is limited until the chlorides are removed to a certain level. ${ }^{14}$ Therefore, the main objective with this treatment is not only to lower the corrosion rate by shifting the polarised potential, but also to use the secondary effect of the current to repulse ions of the same sign. ${ }^{15-17}$ It is implicitly assumed that this repulsion will provoke the lowering of the corrosion rate by the simple disappearance of the chlorides. In fact, simultaneously to the rejection of chlorides, there is produced a build-up of the hydroxide ions due to the cathodic reduction of oxygen (as in the case of $\mathrm{CP}$ ) but also by the water electrolysis: $\mathrm{H}_{2} \mathrm{O}+\mathrm{e}^{-} \rightarrow \mathrm{OH}^{-}+1 / 2 \mathrm{H}_{2}$, with the evolution of hydrogen gas.

The verification of the efficiency of ECE is usually made by drilling cores after the treatment and measuring the remaining chloride content and comparing it with that before the treatment. This is a destructive method. Another manner to verify the condition after the treatment is to measure the corrosion potential or the corrosion rate. The corrosion potential should recover values similar to those typical of lack of corrosion (more anodic than $-350 \mathrm{mV} v$. saturated calomel electrode, SCE) and the corrosion rate should be lower than $0 \cdot 1 \mu \mathrm{A} \mathrm{cm}^{-2}$. However, these values are not always achieved some days after the treatment is finished. ${ }^{14}$ There are not methods to control the advancement of the treatment during its application more than the recording of the charge passed and therefore, the only possibility until now of controlling the progression of the treatments is drilling cores to measure the decrease in the chloride content near the reinforcements.

Regarding ERE, the current applied is also higher than for CP and the treatment is of limited duration. The main objective is to rebuild the alkaline nature of the pore solution surrounding the reinforcements, which is achieved by applying a cathodic current to the bar in order to induce the reduction of oxygen and water aiming into the production of $\mathrm{OH}^{-}$ions. ${ }^{18,19}$ In addition of this generation of $\mathrm{OH}^{-}$, ER tries to induce the electro-osmotic penetration of the carbonate solution that is used as electrolyte in the anodic compartment. The penetration of the carbonate solution helps to the further maintenance of the $\mathrm{pH}$ in values enabling the passivation of the steel.

The verification of the ER efficiency is made by drilling cores and applying phenolphthalein in order to check the change in colour of the indicator. After the treatment, the verification is more seldom made by measuring the corrosion potential or the corrosion rate. Both parameters should return to values indicating the passivation of the steel. There are not developed methods to control the progression of the method during the treatment, more than monitoring the current, ${ }^{20-23}$ assuming potentiostatic application of the treatment. A sudden increase in the current is indicative of the electro-osmotic flux towards the interior.

In the present paper, results on new methods for controlling the efficiency of these treatments are presented. In the case of $\mathrm{CP}$, results of a technique based on measuring the electrochemical impedance in polarised conditions, enables to detect when the treatment is effective. In the case of ECE, the monitoring of the total electrical charge, $I t=Q$, divided by the initial electrical resistance, is illustrated in order to standardise the minimum value needed for enough decrease in chlorides.

In the ER treatment, the monitoring of $Q$ seems feasible through the recording of the current-time evolution: a sudden increase is indicative of the penetration of the external carbonate solution by electro-osmotic forces.

As complementary technique in these two last treatments, ECE and ER, the checking at the end of treatment can be better made by measuring the corrosion rate by the polarisation resistance Method. It has been found that the bars showed values of $I_{\text {corr }}$ $<0 \cdot 1 \mu \mathrm{A} \mathrm{cm}^{-2}$ when the treatments were controlled during its duration with the methods proposed before which enable to verify the achievement of the objectives of removing chlorides or build-up of alkalinity around the bar.

\section{Experimental}

The experimental part attend the three electrochemical repair techniques considered, in order to present the 


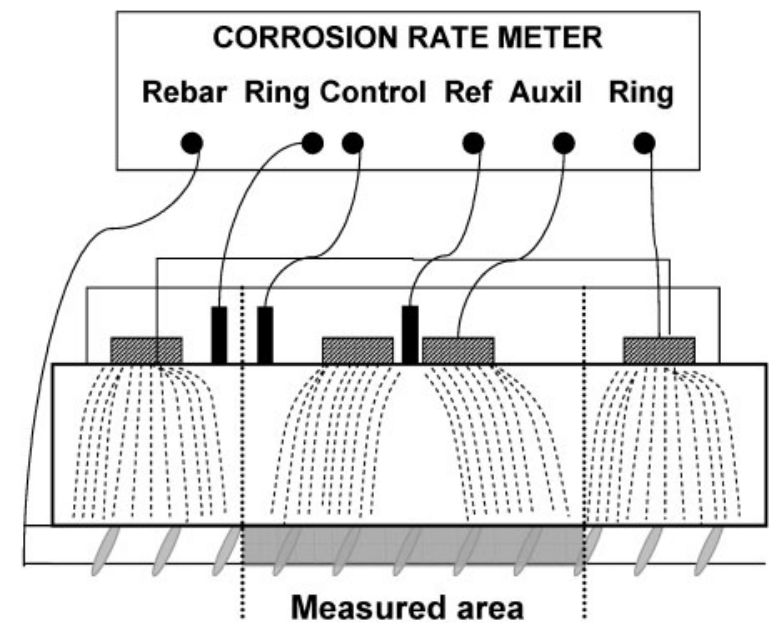

2 Arrangement of double counter electrode in modulated confinement system

trials to demonstrate the proposed methods that better control their efficiency.

\section{Cathodic protection}

For a non-destructive control of some CP systems, it is necessary to try techniques able to be applied without switching off the cathodic polarisation. A method of evaluating the performance of $\mathrm{CP}$ without switching off the cathodic polarisation has been developed using electrochemical impedance spectroscopy (EIS). The method has been patented ${ }^{24}$ as passivity verification technique (PVT). This technique (PVT) is based on the measurement of EIS in the polarised structure. For its application, where the bars have a semiinfinite area, it is necessary to apply a modulated confinement of the current to the specific test area.

Figure 2 shows the arrangement of the double counter electrode (central and guard ring) in order to balance the current applied with the central counter by independent modulation of the current applied by the external guard ring. The correct balance of both internal and external currents is provided measuring the potential drop of the two reference electrodes (ring control in Fig. 2) placed between the central counter electrode and the guard ring. These electrodes are necessary to control an over or under confinement. The circle passing in between both electrical ring control electrodes, which virtually delimitates the polarised area, has a diameter of $10.5 \mathrm{~cm}$ and the diameter of the central counter is $4 \mathrm{~cm}$. The instrument used has been the Gecor 08 .

For the PVT, this instrument applies five different predetermined frequencies $100,10,1,0.1$ and $0.01 \mathrm{~Hz}$, and measures the phase angle between applied and recorded signals. The method has been tested on bare steel members submerged in chloride contaminated solutions and on reinforced concrete slabs, ${ }^{14}$ but it is considered that it could be applied to other electrolytemetal systems. ${ }^{26}$

In the present paper, results of two cases are given:

(i) a concrete slab containing chlorides

(ii) a real structure located in the South of Spain.

\section{Concrete slab}

Figure 3 shows a schematic representation of this case. The size of the reinforced slab was $0.5 \times 0.5 \times 0.1 \mathrm{~m}$, with five carbon steel rebars, $\Phi=8 \mathrm{~mm}$, embedded and oriented all in the same direction. The bars are all externally connected through wires. The rebars presented high corrosion rate values due to the high chloride content in the slab (more than $2 \%$ in cement weight). Chlorides were added during fabrication 10 years ago. A mixed metal oxide coated titanium mesh acting as anode was placed on the bottom part of the slab and a wet sponge of the same size was placed between the concrete and the mesh in order to provide correct electrolytic contact. The electrically connected bars were polarised to a potential of $-1100 \mathrm{mV}$ (on potential) $v$. SCE. Before and after the polarisation, EIS measurements were performed by means of the Gecor 08 with current confinement. The counter electrode of the Gecor 08 was placed on the top of the slab and a sequence of frequencies was applied and the phase angle was recorded.

\section{'Algeciras Market'}

Architect Manuel Sánchez Arcas and Engineer $\mathrm{Mr}$ Eduardo Torroja Miret designed and constructed the 'Mercado Municipal de Algeciras', a project finished in 1935 (Fig. 4). The structure is constituted by a spherical dome of $47.76 \mathrm{~m}$ outside diameter with a radius of curvature $44 \cdot 10 \mathrm{~m}$. supported by a set of eight columns. Additionally, the dome counts with eight cylindrical vaults of radial axis used as a peripheral restrain. The columns are linked together in the upper section by a traction ring. Each of the columns reaches the foundation and is supported by an isolated foot slab. The dome

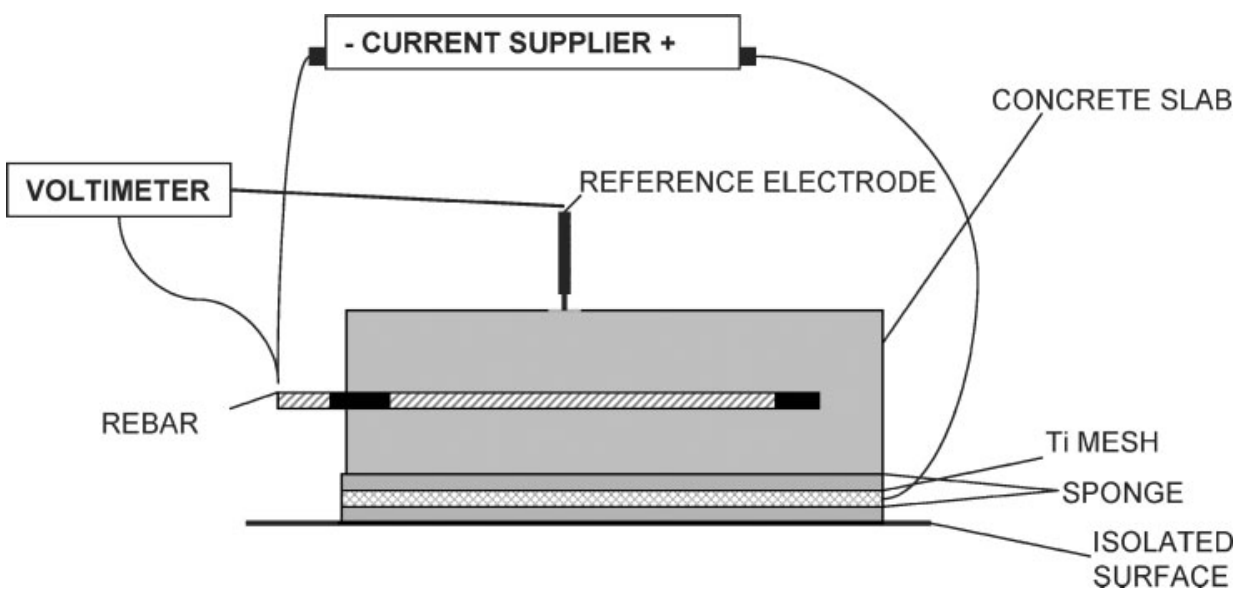

3 Scheme of CP system applied to concrete slab with chlorides 


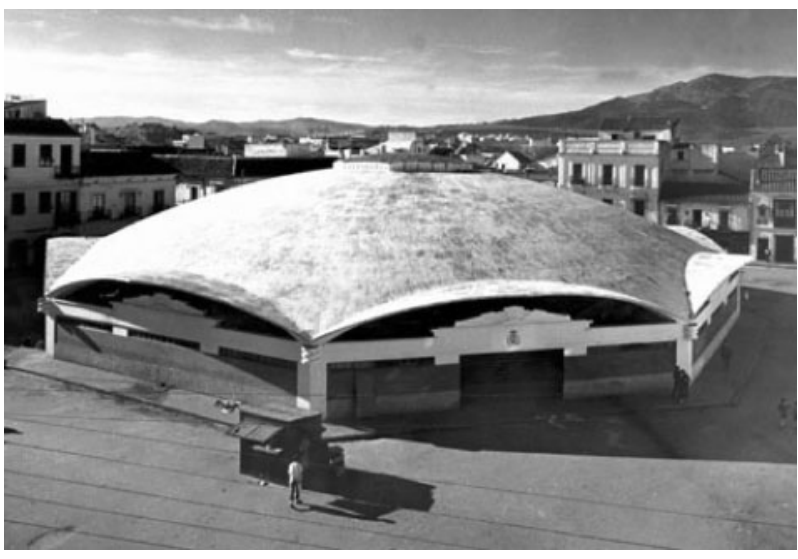

4 Algeciras market

is open in the middle by means of a lantern light of $10 \mathrm{~m}$ in diameter. From the internal part of the dome to its intersection with the cylindrical vaults, the thickness of the sheet is $10 \mathrm{~cm}$. The cylindrical vaults have a thickness of $10 \mathrm{~cm}$ which increases towards the supports.

Owing to chloride attack from the marine wind, the structural elements were showing signs of deterioration. The octagonal ring presented a serious danger for the structural stability, especially because the steel bars could not be replaced. A concrete overlay was added, complementing the ring's traction resistance, and cathodic protection was installed, avoiding the development of further corrosion of the bars.

A continuous coated titanium wire was used for the octagonal ring cathodic protection, injecting the current by a unique rectifier through one point to the hole perimeter, as is shown in Fig. 5. In the figure, it is also shown where the PVT measurements were made. The measurement sensor was located in different zones of the structure with respect to the position of the current injection through the electrical transformer. Points 0,2 and 3 were located in three of the eight pillars of the structure while point 1 was located in the traction ring. In the case of points 1 and 2, some of the measurements were made over the Ti wire anode (marked with *).

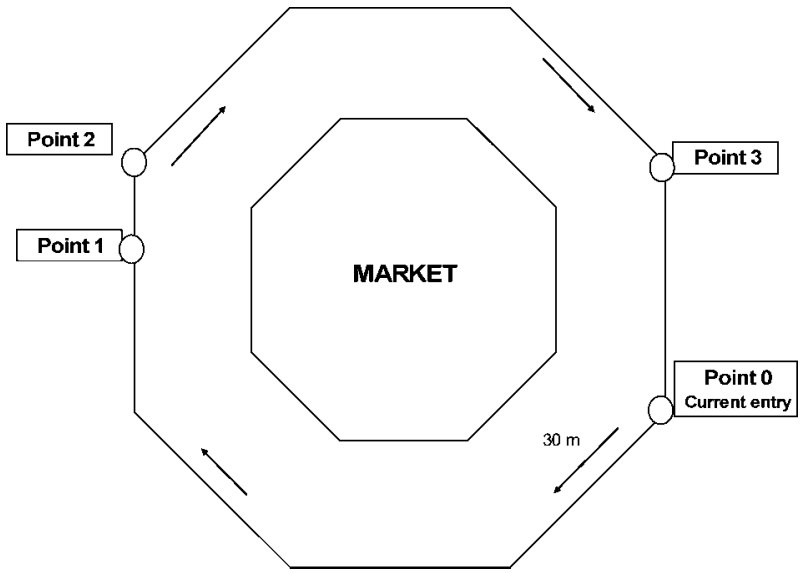

5 Algeciras market: current injection for cathodic protection and measurement points

\section{Electrochemical chloride extraction}

For ECE, there are two possibilities of non-destructive control of the progression of the treatment:

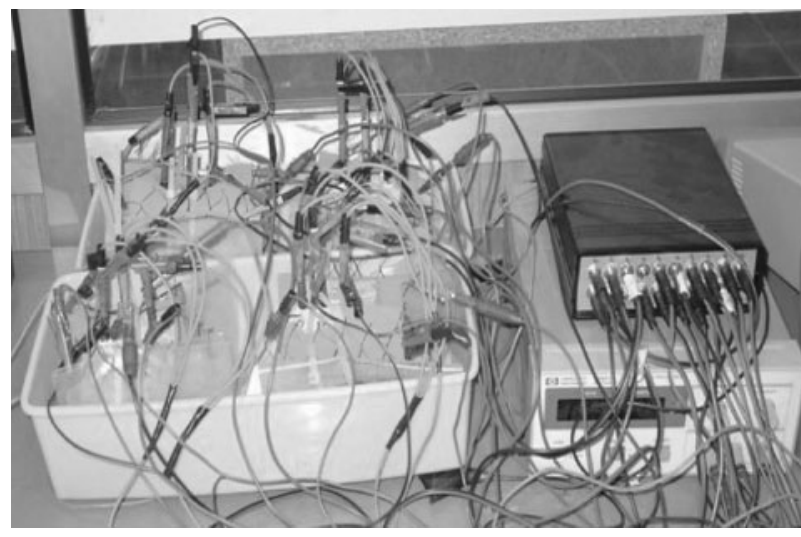

6 Photograph of some trials of ECE running

(i) the monitoring of the electrical charge (coulombs) applied

(ii) the measurement of the corrosion rate at the end of the treatment.

The tests presented here were performed on cubic $7 \times 7 \times 7 \mathrm{~cm}$. paste specimens (Fig. 6) cast with three rebars embedded in their centre, which acted as negative electrodes. Four different binders were tested: plain OPC (CEM I-42.5 R/SR), cement type CEM I-42.5 R/ SR with a $9 \%$ silica fume substitution, cement CEM III B/32.5 SR/NR (among 66 and 80\% blast furnace slag addition) and cement IV-B-32.5 SR/BC, with FA around a $65 \%$ fly ash substitution.

In all the mixes, an amount of $\mathrm{NaCl}$ by mass of cementitious material, ranging from $1 \cdot 2$ and $1 \cdot 5$, was added when casting (the exact value in each mix can be seen in Fig. 7b). The specimens were held in a chamber at $100 \% \mathrm{RH}$ during around 150 days in order to assure the whole maturity of every sample and the establishment of stable potential and corrosion rate values. Then, ECE treatment was performed, applying the electrical
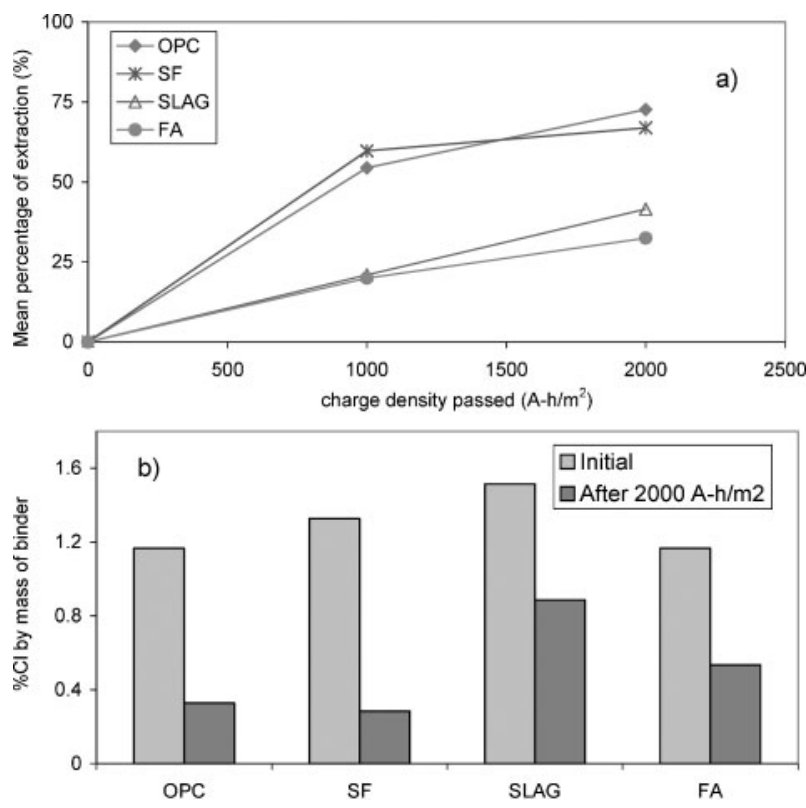

$7 a$ evolution of mean percentage of extraction in samples, in function of charge density passed, and $b$ initial and final amount of chlorides in cathodic part of samples (\% in weight of cement) after maximum amount of charge passed, $2000 \mathrm{Ah} \mathrm{m}^{-2}$ 


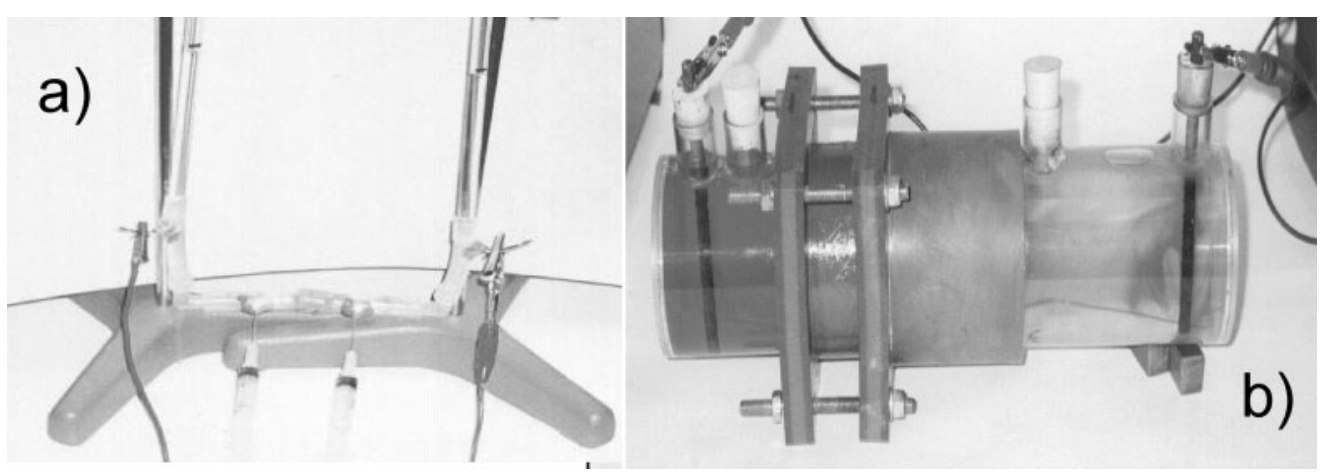

\section{Photograph of experiments with specimens without rebar}

field between an external titanium mesh anode and the rebars embedded in the specimens. The current density applied was $1.4 \mathrm{~A} \mathrm{~m}^{-2}$ during 1 and 2 months, with corresponds to charge densities of 1000 and $2000 \mathrm{Ah} \mathrm{m}^{-2}$ respectively.

Once the experiment is finished, corrosion potential (Ecorr) and polarisation resistance $\left(R_{\mathrm{p}}\right)$ measurements were performed and compared with non-treated specimens. The $R_{\mathrm{p}}$ was measured using a polarisation from -10 to $+10 \mathrm{mV}$ at a sweep rate of $10 \mathrm{mV} \mathrm{min}^{-1}$, and then calculating it from the slope of $\Delta E / \Delta I$ and the corrosion rate through the expression $I_{\text {corr }}=26 \mathrm{mV} / R_{\mathrm{p}}$

\section{Electrochemical realkalisation}

To control the efficiency of the ER, the most common methods are:

(i) control of the electrical charge applied, maintaining it between the recommended limits $0 \cdot 8$ $2 \mathrm{~A} \mathrm{~m}^{-2}$ during $1-2$ weeks

(ii) phenolphthalein test that can be performed at the end of the experiment after drilling cores from the structure.

More scarcely, electrochemical techniques, such as corrosion potential, $R_{\mathrm{p}}$ measurements and potentiostatic anodic polarisation curves, have been used after the treatment. In addition, the authors have used the noticing of the electro-osmotic flux by monitoring the current increase $e^{23,31}$ as the end point of the treatment.

In order to illustrate the advances in ER for monitoring the efficiency during and after the treatment, data from several trials on carbonated $(65 \% \mathrm{RH}$, $20 \pm 2{ }^{\circ} \mathrm{C}$, and $100 \% \mathrm{CO}_{2}$ concentration) OPC matrixes with and without embedded rebar, are reported.

Three different types of samples have been tested:

For the specimens without rebar: (i) on the one hand, small cylinders of $8 \mathrm{~mm}$ diameter and $10 \mathrm{~mm}$ length of normalised OPC mortar on tubular cells, ${ }^{27}$ in which both compartments were made of glass tubes of $4 \mathrm{~mm}$ internal diameter. Two activated titanium wires were used as electrodes. Distilled water was introduced into the compartment where the cathode was located (catholyte), and $0 \cdot 1$ and $0 \cdot 2 \mathrm{M} \mathrm{Na}_{2} \mathrm{CO}_{3}$ solutions were used as anolyte for different experiments. The voltage drop applied between the electrodes was 30 and $12 \mathrm{~V}$ for $0 \cdot 1$ and $0 \cdot 2 \mathrm{M}$ respectively. A photograph of a test running is given in Fig $8 a$

(ii) on the other hand, a disc of $50 \mathrm{~mm}$ thick carbonated OPC concrete has submitted to ER using a 'classical migration cell', as reported in detail in Ref. 10. In this case, two corrugated rebars of $10 \mathrm{~cm}$ in length and $0.6 \mathrm{~cm}$ in diameter were used as electrodes, with a voltage drop of $40 \mathrm{~V}$ applied. The rebar acting as cathode was allowed to freely corrode in distilled water for 2 weeks before the treatment. This precorrosion induced the formation of sufficient rust on the rebar surface. Distilled water was introduced into the catholyte and $1 \mathrm{M} \mathrm{Na} \mathrm{CO}_{3}$ solution was used as anolyte in the anodic compartment. The corrosion rate and the corrosion potential of the rebar acting as cathode was measured before and after the trial by means of the polarisation resistance technique, with the rebar immersed in distilled water and in the final cathodic solution before and after the test respectively. A photograph of the experiment running is given in Fig. $8 b$

(iii) The last trial consists on the realkalisation of a carbonated cylindrical concrete specimen with an

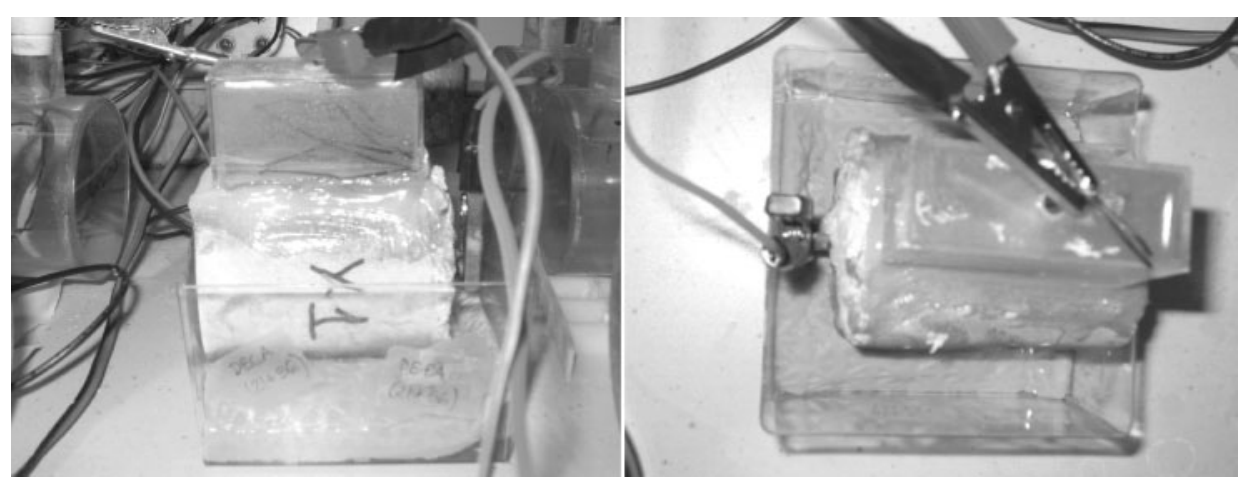

9 Photograph of specimen with rebar used for ER tests 


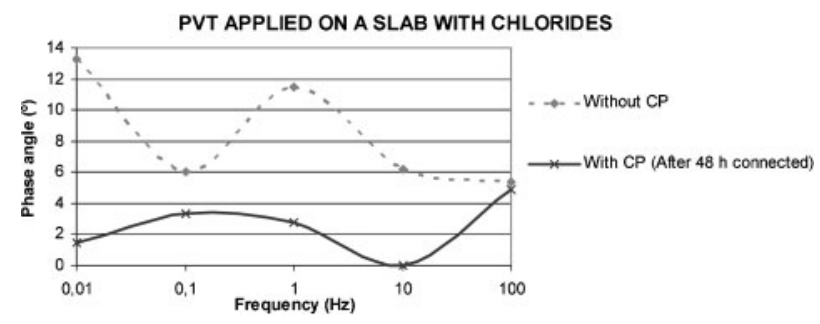

10 Phase angles detected for PVT using modulated confinement (Gecor 08) applied for determination of cathodic protection effectiveness on reinforcement slab with chlorides

embedded rebar acting as cathode. In order to do so, a pounding cell ${ }^{28}$ was used, by gluing a rectangular pool on one side of the specimen parallel to the rebar containing $1 \mathrm{M} \mathrm{Na} \mathrm{Na}_{2} \mathrm{CO}_{3}$ solution, as anolyte, and an external $\mathrm{Ti}$ mesh acting as anode. A voltage drop of $50 \mathrm{~V}$ was applied between the electrodes. A photograph of the experiment running is given in Fig 9. The corrosion rate and the corrosion potential of the rebar acting as the cathode were measured before and after the trial by the polarisation resistance technique.

During all these experiments, the establishment of the electro-osmotic flux by monitoring the abrupt increase in the current intensity during the treatment ${ }^{23}$ was made.

\section{Results}

For the three electrochemical repair techniques, results are presented in relation to the control of the efficiency, as described.

\section{Cathodic protection}

Figure 10 depicts the results obtained in the small slab. The main difference found between unprotected and cathodically protected reinforcements has been previously described ${ }^{25}$ and consist in the displacement of the characteristic frequency of the maximum phase angle of the faradaic process towards higher frequencies, or the lowering of the phase angle values in the range of frequencies from 0.01 to $100 \mathrm{~Hz}$. Then, in Fig. 10, it can be noticed that the plain line obtained after 48 hours of cathodic polarisation shows lower phase angles in the range of frequencies tested than before the $\mathrm{CP}$ treatment (dotted line). This reduction of the phase angle values (mainly from $0 \cdot 01$ to $1 \mathrm{~Hz}$ ) is interpreted as due to the reduction of the corrosion (faradaic process).

The lowering of the angles enable to classify the structure in 'well protected' when at the lowest frequencies tested $(0 \cdot 1$ and $0 \cdot 01 \mathrm{~Hz})$, no faradaic process appears, and 'not protected' when it appears. The 'moderately protected' is an intermediate stage. Following the criteria provided by the PVT, the phase angle results obtained are translated into a percentage of protection, being considered as well protected results higher than $90 \%$ of protection.

Thus, going to the results obtained in the real structure (Algeciras market), it can be deduced from Fig 11 that there are big differences in the polarised potential shown in different perimeter points. This is the consequence of forcing the current to pass through all the octagonal structure being applied only from one point, so, the difference of potential-on from one point close to the transformer to the opposite side is $\sim 400 \mathrm{mV}$ due to the high resistance of the circuit.

In the checking of the cathodic protection efficiency by PVT in the four points mentioned before (Fig. 5), it is

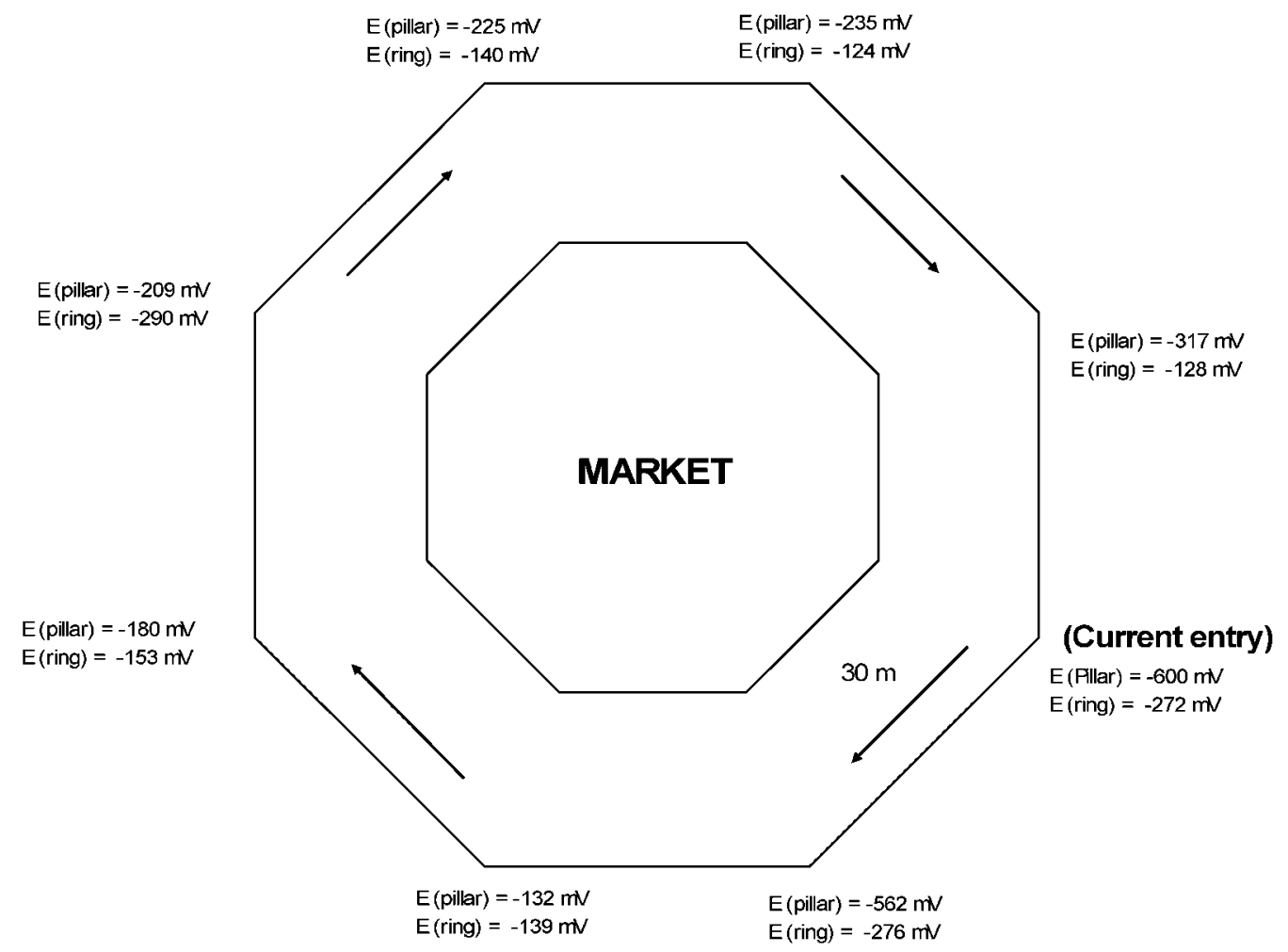




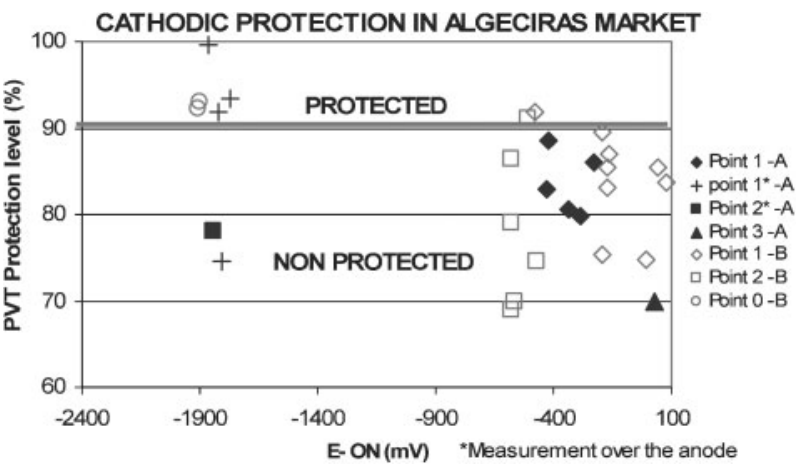

12 Percentage of protection obtained in different areas evaluated in Algeciras market

detected how the level of efficiency is higher as the distance is shorter between the transformer and the measurement point (Fig. 12). So, only point 0 and in some cases, point 1 , have good protection levels, while points 2 and 3 do not reach the accurately level of protection in any case.

Finally, comparing the phase angles measured at each frequency in Fig. 10 obtained in the lab tests, with those in Fig. 13, which represents two measurements made in points 1 and 3 (protected and non-protected area respectively), it can be observed that with similar behaviour, as at frequencies between 0.01 and $1 \mathrm{~Hz}$, phase angles are lower when good protection is detected. In general, when the steel is protected, the phase angles take values lower than $5-10^{\circ}$ in this range of frequencies, being lower as the frequency measured is lower.

\section{Electrochemical chloride extraction}

With respect to non-destructive control of the treatment by means of monitoring of the electrical charge density $\left(\mathrm{Ah} \mathrm{m}^{-2}\right)$ applied, in Fig. $7 a$, the increase in the percentage of extraction of chlorides, averaged for the whole of the sample, is presented. From this figure, it can be deduced that the efficiency in the removal of chlorides is dependent on the binder of the sample, being the efficiencies encountered in the following order.

Plain OPC $\geqslant$ silica fume $>$ slag substituted binder $\geqslant$ fly ashes

These differences are mainly attributed to the different amount of chlorides bounded and to a different resistivity. So, the charge density passed alone is not a reliable indicator of the end point of the treatment, that is, for assuring that enough amount of chloride ions has been extracted and repassivation of the rebars has been achieved. It does not inform on the effect of bound chlorides (bound chlorides release during chloride extraction and then the efficiency will depend on their amount and the release rate) on the ease for chloride removal.

The amount of total chlorides remaining in the cathodic part of the samples after the maximum amount of charge passed, $2000 \mathrm{Ah} \mathrm{m}^{-2}$, is depicted in Fig. 7b, where the initial amount is also given. After 2 months of treatment, smaller values than the limit of $0.4 \%$ of chloride by cement weight are obtained for OPC and SF, while for SLAG and FA (Fig. 7b), the current density passed has not been enough for reaching that level of chloride extraction. This has been attributed to the higher amounts of bound chlorides in slag and FA cements.

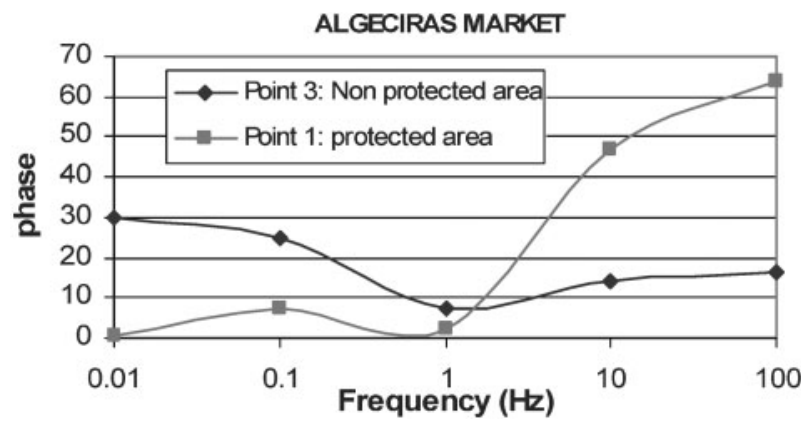

13 Phase angles measured using PVT for determination of cathodic protection effectiveness in Algeciras market

With regard to the efficiency of the treatment in relation with the passivation of the rebars, the corrosion potential and the $R_{\mathrm{p}}$ have been measured in order to determine the corrosion current, and the results obtained are given in Fig. 14. Before the electrochemical treatment, all the specimens had values of potential of corrosion around $-600 \mathrm{mV}(v$. SCE), which is indicative of a high corrosion risk, ${ }^{29}$ and corrosion current higher than $0 \cdot 2 \mu \mathrm{A} \mathrm{cm}^{-2}$, which indicates that all of them were actively corroding. ${ }^{30}$ After the treatment, and maintained along the time (the specimens have been monitored for more than 3 years after finishing the trials), all the values of corrosion potential are maintained in values more positive than $-200 \mathrm{mV}$ which indicates a low corrosion risk. ${ }^{35}$ However, according to the values of corrosion rate, the rebars are passive for the samples OPC and SF. The values for the FA specimens are in the range between $0 \cdot 1$ and $0 \cdot 2 \mu \mathrm{A} \mathrm{cm}{ }^{-2,30}$ which is considered as the border line of active corrosion; in the case of SLAG specimens, certain time after the treatment, the bars showed $I_{\text {corr }}$ values characteristics of active corrosion, which was confirmed by visual inspection of the rebars after the test. Therefore, the $I_{\text {corr }}$ value is the parameter that better correlates with the remaining chloride content.

\section{Electrochemical realkalisation}

Figure 15 shows the evolution of the current passing during the treatment in function of the charge density passed $\left(\mathrm{Ah} \mathrm{m}^{-2}\right)$ for the different experiments. Figure 15 reports the data corresponding to the specimens without and with embedded rebar respectively. Provided that the voltage applied in the different experiments was not the same, for the sake of clarity, in Fig. $15 a$, the values of current have been normalised to the initial value passing through the specimens.

In this figure, it can be detected that as the realkalisation proceeds, there are one (or several) points in which there is a sudden increase in the circulating current. These increases have been detected in every experiment performed and a parallelism between the sudden increase in the current and the electro-osmotic flux has been shown. ${ }^{11}$

The limits for the typical recommended values of charge density passed during the test have been marked as vertical lines in Fig. 15. These limits are $0.8 \mathrm{~A} \mathrm{~m}^{-2}$ during 1 week as the lower limit and $2 \mathrm{~A} \mathrm{~m}^{-2}$ during 2 weeks as the higher one. From the comparison of this range and the charge densities at which the electroosmotic flux takes place, it can be deduced that in most 

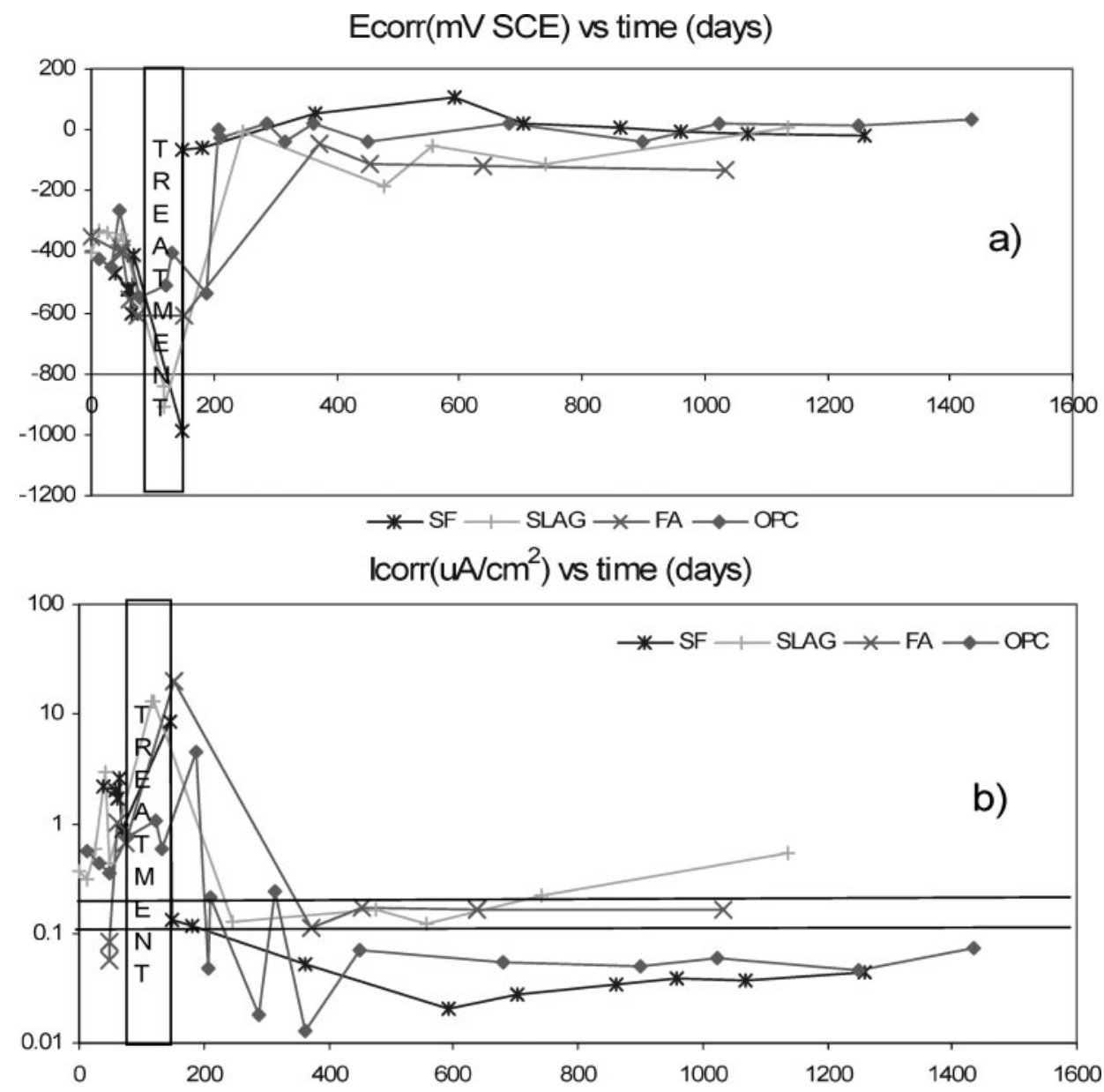

14 Evolution of $a E_{c o r r}$ and $b I_{c o r r}$ before and after ECE treatment for all specimens studied

cases, the recommended values of charge densities are not enough for developing the electro-osmotic flux.

In Fig. 16, the corrosion potential and the $R_{\mathrm{p}}$ of the rebars used in the different experiments are depicted. In the concrete without the rebar embedded, tested in the migration cell, ${ }^{10}$ the steel was immersed in distilled water as initial cathodic solution, before the ER trial. After the experiment, the steel was left in the final cathodic solution in the open air, the $\mathrm{pH}$ of this solution just after finishing the ER treatment was $13 \cdot 2$, and evolved in contact with the atmospheric $\mathrm{CO}_{2}$ reaching a final $\mathrm{pH}$ of the approximately constant, of $10 \cdot 3,45$ days after the treatment was finished.

Before the electrochemical treatment, both specimens were actively corroding, with values of potential of corrosion around $-600 \mathrm{mV} v$. SCE for the rebar corroding in distilled water and around $-250 \mathrm{mV} v$. SCE for the rebar embedded in the carbonated concrete, and a corrosion current much higher than $0 \cdot 2 \mu \mathrm{A} \mathrm{cm}^{-2}$. After the ER treatments, the steels present very high $I_{\text {corr }}$ values for a short period and decreases afterwards. In the steel, in the cathodic solution of the migration cell, it
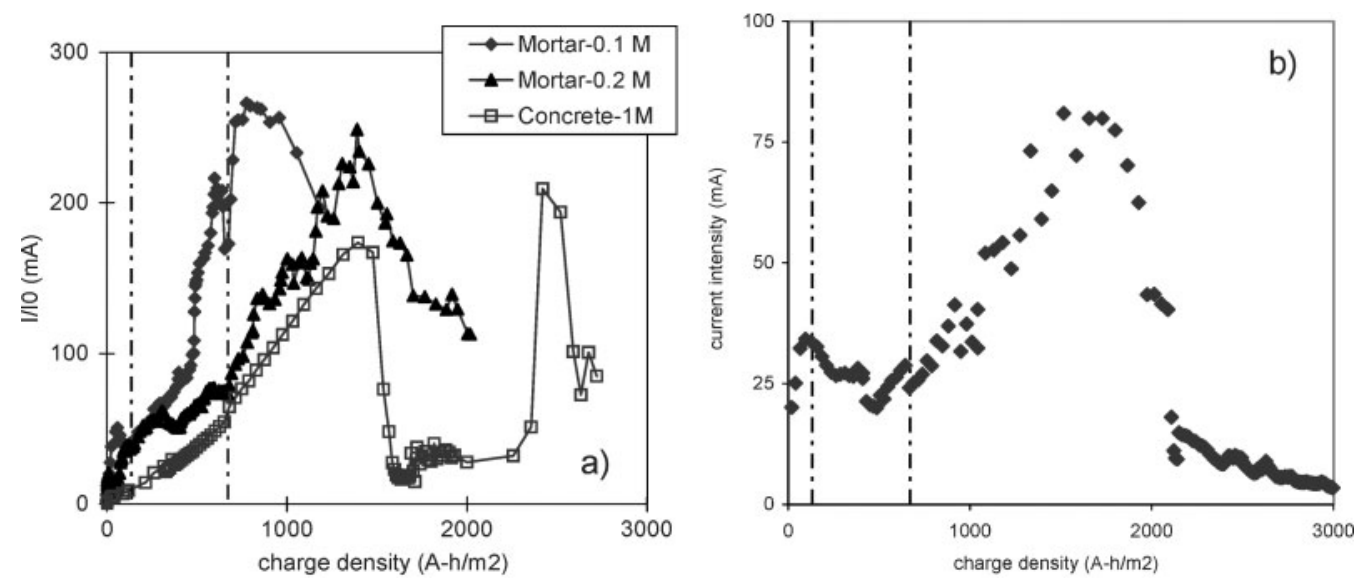

$a$ specimens without embedded rebar; $b$ specimen with embedded rebar

15 Evolution of current during ER treatment in function of charge density passed $\left(\mathrm{Ah} \mathrm{m}^{-2}\right)$ for different experiments: vertical dotted lines are limits for recommended values of charge density passed 

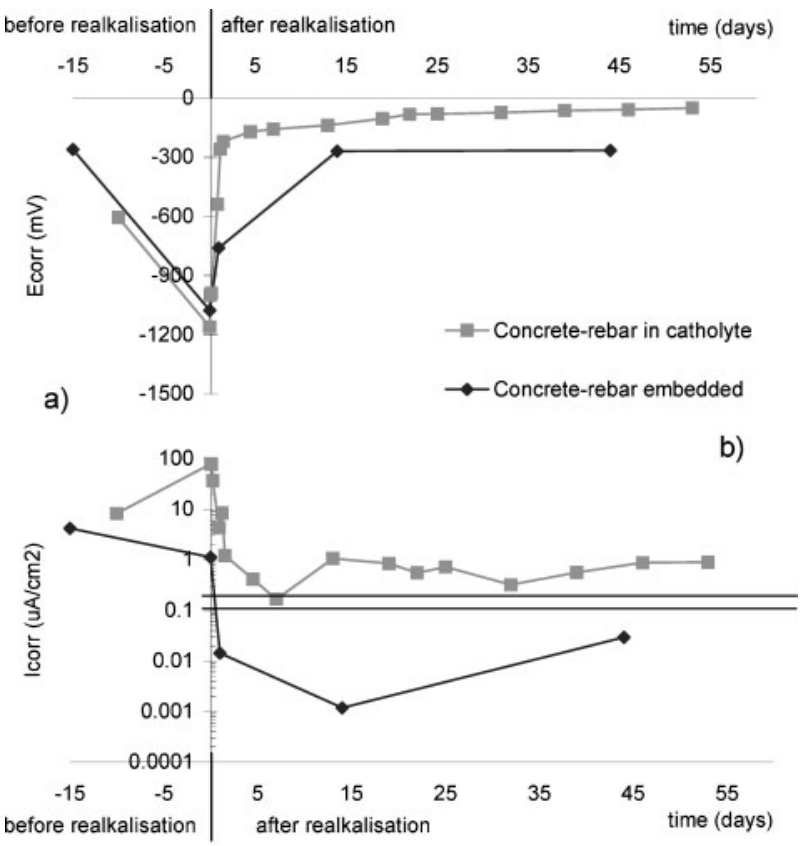

16 Evolution of a corrosion potential and $b R_{\mathrm{p}}$ of rebars before and after ER experiments

remains active during the 2 months recorded while in the embedded rebar, the steel repassivates.

\section{Discussion}

\section{Techniques to measure and monitoring efficiency \\ Cathodic protection}

The efficiency is being controlled measuring: the current applied, the instant-off potential or the shift of instantoff potential after 4-24 hours of disconnecting the current. These methods have important limitations when using systems in which is not possible to interrupt the current, as the instant-off potential and the shift of instant-off potential need the disconnection of the system. Therefore, to have alternative techniques of control is of great interest.

Effective repassivation of the steel is the main goal of a repair technique and therefore, the efficiency control should be devoted to the verification of the lowering of the corrosion rate values until levels indicate the restoration of the passive state. The most suited technique is the measurement of the $R_{\mathrm{p}}$ as has been demonstrated in numerous papers. ${ }^{31,32}$ However, in the case of $\mathrm{CP}$, the measurement of the $I_{\text {corr }}$ is not a correct indication unless the current is disconnected and the steel is allowed to be depolarised. If the steel is cathodically polarised, the $I_{\text {corr }}$ values will be very high because what is really measured through the $R_{\mathrm{p}}$ method is the current applied. ${ }^{33}$ Therefore, $R_{\mathrm{p}}$ is not a suitable technique to indicate $\mathrm{CP}$ efficiency.

Being the current applied in CP lower than for ECR and ER, the effects are shorter when current is not applied and this prevents of proposing the measurement of $R_{\mathrm{p}}$ after switching off the current.

However, if instead of measuring $R_{\mathrm{p}}$, what is measured is the phase angle by AC impedance method, their values and the range of frequencies in which a maximum is detected will inform on whether there is or not a faradaic (active corrosion) process going on. This is the basis of the PVT, which enables to know whether an active corrosion is being developed or not.

\section{Realkalization and chloride removal}

In ECE and ER, there are two moments in which it is necessary to measure the efficiency of the treatments:

(i) during their application in order to decide when the treatment finishes

(ii) after the treatment, in order to monitor the maintenance of the repassivation achieved.

\section{During treatment application}

For ECE, enough efficiency was assumed if a certain total electrical charge density, $Q\left(\mathrm{Ah} \mathrm{m}^{-2}\right)$ has been passed. ${ }^{14}$ However, present results show that due to the different microstructural characteristics of the different cement types (indicated by the resistivity) and their different binding ability, this parameter is not reliable enough to inform on the reinstalling of passivity. To respond to this challenge, one possibility is to divide the charge density that is intended to be applied, $Q$, by the electrical resistance just at the beginning of the treatment. In the present experimentation, this will give the results shown in Fig. 17a, where the initial electrical resistance of the samples is also given. In Fig. $17 a$ it can be seen that the mixes for which the repassivation has not been reached exhibit values of $Q / R$ below $1800 \mathrm{Ah} \mathrm{m}{ }^{-2} \mathrm{k}^{-1}$. Thus, a new control parameter is proposed: the 'standardised by the resistance charges (SRC), which would be a more indicative parameter than the simple recording of coulombs to check the efficiency during ECE treatment. A threshold of $1800 \mathrm{Ah} \mathrm{m}^{-2} \mathrm{k}^{-1}$ could be a suitable value. Taking this value as a threshold, in the present research, the charge density that would have been enough for

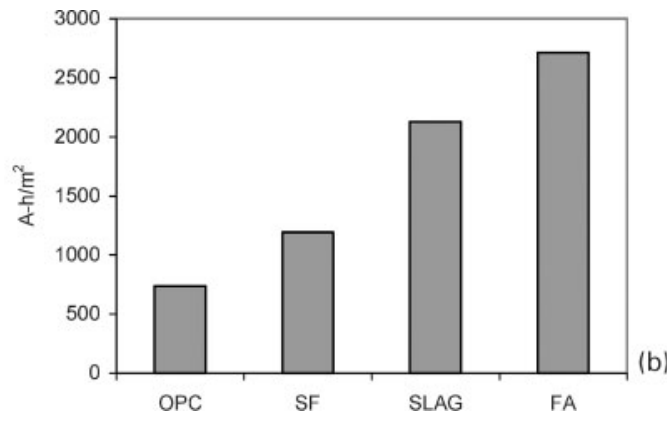

$17 a Q / R$ calculated at end of experiment: at top of each bar, initial resistance of samples ( $\mathrm{k} \Omega$ ), and $b$ charge density passed that would have been enough for reaching whole passivation, taking $1800 \mathrm{Ah} \mathrm{m}^{-2} \mathrm{k}^{-1}$, as threshold value for SRC 
reaching whole passivation is depicted in Fig. 17b, where it can be seen that for the OPC samples, this is just $750 \mathrm{Ah} \mathrm{m}^{-2}$ while for the FA samples, would have needed $2700 \mathrm{Ah} \mathrm{m}^{-2}$.

For measuring the progress of ER, the present results have shown that the total charge is not only insufficient in the value recommended until now, but it is also not enough if a sudden increase (the peaks of Fig. 15) is not recorded, because these peaks are the only clear indication of the developing of the electro-osmotic flux.

In Ref. 34, a set of different tests at different charge densities passed indicated that after 5 days of treatment at $1000 \mathrm{~mA} \mathrm{~m}^{-2}\left(120 \mathrm{Ah} \mathrm{m}^{-2}\right)$, the rebar was realkalised not only by measuring the colorimetric depth of phenolphthalein, but also by potentiostatic anodic polarisation curves. However, measuring corrosion rate by the polarisation resistance method 3 months after the treatment, the steel was still depassivated. The sodium distribution in the specimen was analysed, with the conclusion that 'only with conditions unusual for application (i.e. $5000 \mathrm{~mA} \mathrm{~m}^{-2}$ during 14 days) a significant increase up to the reinforcement level was achieved'. That condition implies the passage of $1680 \mathrm{Ah} \mathrm{m}^{-2}$, which lies in the charge density in which, according to present results, the electro-osmotic flux is likely to occur (Fig. 15).

\section{After treatment}

The measurement of the corrosion potential and definitively, the measurement of the $R_{\mathrm{p}}$, have been the best techniques to monitor the maintenance of the repassivation, even 3 years after, in the case of ECE. Regarding realkalisation, the phenolphthalein test is not enough to prove the state of the steel surface, ${ }^{34,35}$ as it has been proved after electrochemical measurements on realkalised specimens that turned pink after applying the acid basic indicator, and showed high corrosion levels. The corrosion rate obtained from the $R_{\mathrm{p}}$ is the most reliable indication of lack of corrosion ${ }^{8,35}$ and it has enabled to verify that efficient repassivation is feasible if the correct treatment conditions are applied.

\section{Repassivation ability of the techniques}

Regarding CP, it is well accepted by the scientific and engineering community that it is an efficient technique to stop corrosion if well applied. The big amount of data recorded in other systems, as well as the long experience in concrete structures ${ }^{2}$, indicate that the $\mathrm{CP}$ is a suitable technique to stop the corrosion process. A very simple test was reported in Ref. 25 to show this.

There is not the same perception with respect to ECE and RE, as there have been recent publications ${ }^{36}$ stating that repassivation or lowering of the corrosion rate of the steel already deteriorated by corrosion, is not possible. This is more dramatic for the ER than for ECE, where it is recognised that it removes chlorides and when corrosion does not decreases, it is attributed to an insufficient removal. However, in the case of ER, there are papers where, in spite of noticing the increase in the $\mathrm{pH}$ around the bars after the treatment, repassivation of the steel bars is reported not to be found. ${ }^{34}$ This lack of repassivation is feasible if the treatment is not well applied.

In the present experimentation, it has been found that steel can repassivate in both types of treatments, providing certain conditions are fulfilled. Thus, in the
ECE applied to pastes fabricated with four different cement types, evidences show that corrosion remains active when the chloride not removed is above the threshold (Fig. 7), and therefore, chlorides which have to be checked to have been removed. In the case of ER, the reason for the non-repassivation is that the charge density passed seems to be insufficient for getting the electroosmotic flux (Fig. 15, where the peaks of maximum current are not reached for the nominal current usually prescribed). Then in both techniques, ECE and ERE, it is necessary to check the efficiency, not only through the application of a certain initial current or charge, but also by the techniques analysed in the present work.

In summary, the $\mathrm{CP}$ and the new electrochemical repair techniques need more reliable and non-destructive methods to check their efficiency. The differences between them lie mainly in the duration and the level of current applied. A threshold of $1800 \mathrm{Ah} \mathrm{m}^{-2} \mathrm{k} \Omega^{-1}$ of corrected charge density passed enables to account the level of chloride removal, while the appearance of current peaks linked to the electro-osmosis is needed for ER, and therefore, it should serve to control and monitor the degree of repassivation provided, but finally, it is at the steel where the repassivation has to be checked and the $R_{\mathrm{p}}$ technique is the most suitable candidate to be used.

\section{Conclusions}

The present results enable to draw up the following conclusions regarding the three repair techniques evaluated:

1. The measurement of EIS without disconnecting the current is a good alternative informative method for the $\mathrm{CP}$ efficiency control. The frequencies at which the faradaic process should appear serve to notice the presence/absence of active corrosion.

2. Chloride removal should be measured during the treatment through the amount of effective electrical charge passing through, standardised by the electrical resistance measured at the beginning of the treatment, SCR. This parameter should be at least of $1800 \mathrm{Ah} \mathrm{m}^{-2} \mathrm{k}^{-1}$.

3 . The realkalisation is only efficient if an electroosmotic flux of carbonate is induced to penetrate until the bar, which can be noticed during the treatment by means of sudden dramatic increase in the current monitored. Only in these conditions, realkalisation can be fully effective.

4. The recommended values of charge density passed for the realkalisation treatments ( 14 days at $\left.2 \mathrm{~A} \mathrm{~m}^{-2}\right)$ in most cases seem to be insufficient for getting the electroosmotic flux in most of the cases. An amount above $1700 \mathrm{Ah} \mathrm{m}^{-2}$ is recommended.

5. The measurement of $R_{\mathrm{p}}$ after ECR or ER is a reliable indication of the degree of steel repassivation, and enables the monitoring during aging. When the $I_{\text {corr }}$ values maintain in levels above $0 \cdot 1 \mu \mathrm{A} \mathrm{cm} \mathrm{cm}^{-2}$ after some days or weeks, the treatment has not been efficient enough and new treatment periods should be considered.

\section{Acknowledgement}

The authors are grateful to funding of the Ministry of Education and Science of Spain through the project of 
the programme SEDUREC CONSOLIDER-2006 INGENIO 2010.

\section{References}

1. C. Wagner: J. Electrochem. Soc., 1952, 99, (1), 1-12.

2. D. A. Hausmann: Mater. Prot., 1969, 8, (10), 23-25.

3. L. Bertolini, M. Gastaldi, M. P. Pedeferri, P. Pedeferri and E. Redaelli: Proc. COST 521 Workshop, (ed. J. Mattila); 2001, Tampere, Department of Civil Engineering.

4. 'Cathodic protection of reinforcing steel in atmospherically exposed structures', RPO290-90, NACE, Houston, TX, USA, 1990

5. Concrete Society: 'Cathodic protection of reinforced concrete', Tech Report no. 36, Concrete Society, Surrey, UK, 1989.

6. CUR: 'Kathodische bescherming van wapening in betonconstru' (Cathodic protection of reinforcement in concrete structures), CUR Tecb Recommendation 45, CUR, Gouda, The Netherlands, 1996.

7. 'Cathodic protection of steel in concrete', EN12696, CEN, Brussels, Belgium, 2000

8. B. Elsener: Contr. Build. Mater., 2001, 15, (2-3), 133-139.

9. R. Polder: 'Electroosmosis in concrete. Theory, basic and field data and preliminary tests', TNO-report 93-BT-R1423, TNO, Brussels, Belgium, 1993

10. C. Andrade, M. Castellote, J. Sarría and C. Alonso: Mater. Struct., 1999, 32, 427-436.

11. M. Castellote, I. Llorente, C. Andrade, X. Turrillas, C. Alonso and J. Campo: Cem. Concr. Res., 2006, 36, 791-800.

12. R. Polder: in 'Corrosion of steel in reinforced concrete structures', Final report; 2002, Luxembourg.

13. M. Pourbaix: 'Atlas of electrochemical equilibria in aqueous solutions'; 1976, Houston, TX, NACE.

14. M. Castellote, C. Andrade and C. Alonso: Cem. Concr. Res., 2000, 30, 615-621.

15. J. E. Bennet and T. S. Schue: Proc. Conf. Corrosion '90, Las Vegas, NV, USA, April 1990, National Association of Corrosion Engineers, Paper 316.

16. M. Castellote, C. Andrade and C. Alonso: Adv. Cem. Res., 1999, 11, (2), 63-80

17. R. Polder and H. J. van der Hondel: Mater. Struct., 1993, 26, 185189.
18. J. B. Miller: Proc. Int. Conf. on 'Corrosion and protection of steel in concrete', Sheffield, UK, July 1994, University of Sheffield.

19. P. F. G. Banfill: Proc. Int. Conf. on 'Corrosion and protection of steel in concrete', Sheffield, UK, July 1994, University of Sheffield.

20. Ø. Vennesland: Proc. Nordisk Beton Kong., Odense, Denmark, 1987.

21. J. Mietz: 'Electrochemical rehabilitation methods for reinforced concrete structures, a state of the art report', Publications No. 24; 1998, London, IOM Communications.

22. 'Electrochemical realkalisation and chloride extraction treatments for reinforced concrete - Part 1. Realkalisation', prEN 140381:2000, CEN, Brussels, Belgium, 2000.

23. R. Polder: 'Corrosion of steel in reinforced concrete structures', Final Report on 'electrochemical maintenance methods', (ed. R. Wydert), 123-164; 2000 .

24. C. Andrade, J. Fullea, J. A. Bolaño, F. Jiménez, A. Navarro and I. Martínez: patent no. ES2151410, 2003.

25. C. Andrade, I. Martínez and X. R. Nóvoa: Proc. 15th Int. Corrosion Cong. (ICC), Granada, Spain, September, 2002.

26. C. Andrade, I. Martínez, F. Jiménez and A. Navarro: Proc. Conf. CEOCOR 2001, Biarritz, France, October 2001.

27. M. Castellote, I. Llorente and C. Andrade: Mater. Constr., 2003, 53, (271-272), 101-111.

28. M. Castellote, I. Llorente and C. Andrade: Cem. Concr. Res., 2006, 6, 1915-1921.

29. 'Standard test method for half-cell potentials of uncoated reinforcing steel in concrete', C-876-91, ASTM, Philadelphia, PA, USA, 1995.

30. T. C. Rilem: Mater. Struct., 2004, 37, 623-643.

31. C. Andrade and J. A. Gonzalez: Werkst. Korros., 1978, 29, 515.

32. C. Andrade, I. Martínez, C. Alonso and J. Fullea: Mater. Constr., 2001, 51, 263-264.

33. C. Andrade, I. Martínez, I. Lasa, O. Tronconis de Rincón, A. A. Torres-Acosta and M. Martínez: Proc. Conf. Corrosion 2004 Houston, TX, USA, March 2004, Paper 04329.

34. J. Mietz: Werkst. Korros., 1995, 46, (9), 527-533.

35. W. Yeih and J. J. Chang: Constr. Build. Mater., 2005, 19, (7), 516 524

36. J. M. Miranda, J. A. González, A. Cobo and E. Otero: Corros. Sci., 2006, 48, (8), 2172-2188. 